\title{
Irish general practitioner attitudes toward decriminalisation and medical use of cannabis: results from a national survey
}

\author{
Des Crowley ${ }^{2}$, Claire Collins ${ }^{2}$, Ide Delargy ${ }^{2}$, Eamon Laird ${ }^{3}$ and Marie Claire Van Hout ${ }^{1,2^{*}}$ (D)
}

\begin{abstract}
Background: Governmental debate in Ireland on the de facto decriminalisation of cannabis and legalisation for medical use is ongoing. A cannabis-based medicinal product (Sativex ${ }^{\circledR}$ ) has recently been granted market authorisation in Ireland. This unique study aimed to investigate Irish general practitioner (GP) attitudes toward decriminalisation of cannabis and assess levels of support for use of cannabis for therapeutic purposes (CTP).
\end{abstract}

Methods: General practitioners in the Irish College of General Practitioner (ICGP) database were invited to complete an online survey. Anonymous data yielded descriptive statistics (frequencies, percentages) to summarise participant demographic information and agreement with attitudinal statements. Chi-square tests and multi-nominal logistic regression were included.

Results: The response rate was 15\% $(n=565)$ which is similar to other Irish national GP attitudinal surveys. Over half of Irish GPs did not support the decriminalisation of cannabis (56.8\%). In terms of gender, a significantly higher proportion of males compared with females ( 40.6 vs. $15 \% ; p<0.0001)$ agreed or strongly agreed with this drug policy approach. A higher percentage of GPs with advanced addiction specialist training (level 2) agreed/strongly agreed that cannabis should be decriminalised (54.1 vs. $31.5 \% ; p=0.021$ ). Over $80 \%$ of both genders supported the view that cannabis use has a significant effect on patients' mental health and increases the risk of schizophrenia (77.3\%). Over half of Irish GPs supported the legalisation of cannabis for medical use (58.6\%). A higher percentage of those who were level 1-trained (trained in addiction treatment but not to an advanced level) agreed/strongly agreed cannabis should be legalised for medical use $(p=0.003)$. Over $60 \%$ agreed that cannabis can have a role in palliative care, pain management and treatment of multiple sclerosis (MS). In the regression response predicator analysis, females were $66.2 \%$ less likely to agree that cannabis should be decriminalised, $42.5 \%$ less likely to agree that cannabis should be legalised for medical use and 59.8 and $37.6 \%$ less likely to agree that cannabis has a role in palliative care and in the treatment of multiple sclerosis (respectively) than males.

Conclusions: The majority of Irish GPs do not support the present Irish governmental drug policy of decriminalisation of cannabis but do support the legalisation of cannabis for therapeutic purposes. Male GPs and those with higher levels of addiction training are more likely to support a more liberal drug policy approach to cannabis for personal use. A clear majority of GPs expressed significant concerns regarding both the mental and physical health risks of cannabis use. Ongoing research into the health and other effects of drug policy changes on cannabis use is required.

Keywords: Cannabis, Decriminalisation, Legalisation, Medical use, Cannabis for therapeutic purposes (CTP), General practitioner

\footnotetext{
* Correspondence: mcvanhout@wit.ie

${ }^{1}$ School of Health Sciences, Waterford Institute of Technology, Waterford,

Ireland

${ }^{2}$ Irish College of General Practitioners, Dublin, Ireland

Full list of author information is available at the end of the article
}

\section{Biomed Central}

(c) The Author(s). 2017 Open Access This article is distributed under the terms of the Creative Commons Attribution 4.0 International License (http://creativecommons.org/licenses/by/4.0/), which permits unrestricted use, distribution, and reproduction in any medium, provided you give appropriate credit to the original author(s) and the source, provide a link to the Creative Commons license, and indicate if changes were made. The Creative Commons Public Domain Dedication waiver (http://creativecommons.org/publicdomain/zero/1.0/) applies to the data made available in this article, unless otherwise stated. 


\section{Background}

Cannabis is the most prevalent illicit drug used globally [1]. The policy landscape around cannabis is dynamic [2], with three drug policy options available, prohibition, decriminalisation and legalisation [3]. In recent years, the legal status of cannabis has been extensively debated in academic and policy domains, with many jurisdictions making or considering major changes in their domestic laws and policies on this issue. The International Centre for Science in Drug Policy have advised that such policy responses need to be based on best available evidence [4].

The United Nations (UN) Drug Conventions support the prohibitionist approach and require signatories to make the possession of cannabis a criminal offence under their domestic laws [5]. Policy makers challenging this approach argue that the criminalisation of cannabis is an expensive and ineffective drug control policy which has no impact on reducing availability or use despite its significant financial costs [6]. Proponents for policy change support a less punitive approach to cannabis users with a greater emphasis on public health and human rights $[2,5,6]$. The decriminalisation drug policy approach involves the removal of criminal sanctions for those found in possession of small amounts of the drug for their own use [5]. However, the use of the drug is not legal, and non-criminal offences may still be applied [5]. Underpinning this approach is the argument that cannabis is a relatively safe drug when compared to alcohol and tobacco, and criminal sanctions for personal use and possession of small amounts are excessive [6]. Prohibitionist continues to argue that removal of criminal barriers will lead to increased supply, use, dependence and harm [3].

With increasing public support for the decriminalisation of cannabis use, some jurisdictions are now developing and implementing a range of legally regulated market models for recreational cannabis use [2]. Legalisation of cannabis usually refers to the removal of all criminal and non-criminal sanctions for its use, production and supply. However, legal regulation will set out the rules and restrictions around how these can occur [5].

Despite widespread prohibition, many multiple sclerosis and chronic pain patients use cannabis for analgesia and psychological support [7]. Some states in the USA have moved toward allowing individuals to use cannabis for medical purposes [5], with resultant debate on whether these laws have led to increased use [8]. Debates around legalisation of medical cannabis centre on the beliefs that cannabis has medical effects, medical cannabis is addictive and that legalisation leads to increased use for recreation (i.e. spillover effects) [9]. Some reports indicate the potential value of cannabis for therapeutic purposes (CTP) [10-15]. However, some concerns around the addictive potential of cannabis are evident $[4,5,16]$ but with a weak evidence base indicating lower probability of dependence and physical and social harm when compared to alcohol, cocaine, opiates and nicotine [4]. Legalisation in the form of de facto legal supply for medical use (CTP) does not appear to have created a significant threat to public health and safety, or caused increased consumption or related harms [17-20]. In terms of patient experience, legalisation appears to increase patient's feelings of safety and awareness [21].

To date, eight US states (Alaska, California, Colorado, Oregon, Massachusetts, Maine, Nevada and Washington) have now voted to legalise cannabis for both medical and non-medical use, and one state (Washington DC) has legalised it for personal use but not commercial sale [5]. Regulatory debates are ongoing in many countries including Canada, Jamaica, Italy, Spain, several Latin American countries and additional US states [5].

To date, research on medical practitioner views on this issue remains scant [17]. In the past 20 years, only a minority of oncologists surveyed in the USA were in support of the rescheduling of cannabis for medical purposes [22] and the availability of cannabis on prescription [23]. More recently, in the USA, medical practitioner views on medical cannabis are generally less supportive of medical use, underpinned by recognition of its potential for serious mental and physical health risks [24, 25]. Israeli practitioners have voiced partial acceptance for therapeutic use, with further research warranted to investigate educational and regulatory needs [26]. Israeli rheumatologists in 2016 report majority opinion of some role for cannabinoids in the management of rheumatoid disease [27].

Our study is the first of its kind in Ireland and aimed to investigate Irish general practitioner (GP) attitudes toward decriminalisation of cannabis and assess levels of support for CTP. The study was undertaken on foot of several regulatory developments and debates in Ireland, in particular, a recent governmental debate and reporting from the Oireachtas Justice Committee on the proposed decriminalisation of cannabis. The committee recommended that possession of small amounts of cannabis for personal use should not be dealt with through the criminal justice system and that small-scale users should be treated with compassion. Other debates centred on CTP in Ireland with authorisation necessary from the Health Products Regulatory Authority (HPRA) or, in the case of certain medicinal products, the European Medicines Agency (EMA). In July 2014, regulations were amended to allow for certain cannabis-based medicinal products to be used in Ireland. The HPRA granted a marketing authorisation for a cannabis-based medicinal product $\left(\right.$ Sativex ${ }^{\circ}$ ) which is indicated for the treatment of spasticity for people with multiple sclerosis. However, the most recent national treatment data indicates cannabis is the most common problem drug among new cases presenting for drug treatment [28]. 


\section{Methods}

In Ireland, medical training for general practitioners is overseen by the Irish College of General Practitioners (ICGP). Training in substance misuse is provided as levels 1 and 2 training. GPs trained to these levels have acquired additional knowledge and experience in the treatment and management of substance use problems. Ethical approval was granted by the ICGP. In early 2016, an online survey was undertaken with all GPs in the ICGP database based in the Republic of Ireland. Electronic invitations included information on the study and consent information, and a link to access the online survey was sent. A notice encouraging response was also placed on the substance misuse section of the ICGP website. The survey was designed based on a review of the literature and in consultation with the project team. The instrument contained a series of closed questions relating to participant profile and practice location, specialist registration, experience in treating opioid users and their responses toward a five-point Likert scale measuring agreement with a series of statements. Statements measured attitude toward decriminalisation of cannabis, legalisation for CTP, potential for decriminalisation to increase cannabis use, adverse mental and physical health effects of cannabis use, cannabis use in young people and risk of development of schizophrenia and role of CTP in pain management, treatment of multiple sclerosis and palliative care. The survey took an estimated $10 \mathrm{~min}$ to complete. While the response rate for this online survey was low (15\%), it is consistent with the response rates from GPs nationally and internationally for similar type of studies [29-31].

Anonymous data yielded descriptive statistics (frequencies, percentages) to summarise participant demographic information and agreement with attitudinal statements. Statistical analysis was performed using the Statistical Package for Social Sciences (Version 21.0; SPSS UK Ltd; Chersey, UK). Where appropriate, chi-square tests were applied to determine the statistical significance $(p<0.05)$. Multi-nominal logistic regression analysis was used to determine predictors of answer responses with the neutral response category as the reference.

\section{Results}

\section{Participant characteristics}

The participant characteristics are displayed in Table 1. There was no significant difference in the proportion of males or females sampled $(p=0.180)$. The majority of males $(50.5 \%)$ tended to be older ( $>50$ years), while the majority of females were aged between 30-50 years (62.4\%). Most of the participants were full-time practitioners, $(71.3 \%)$ though significantly more males were retired compared with females (8.6 vs. $4.2 \% ; p=0.030$ ), while significantly more females were trainees (23.0 vs.
$15.1 \% ; p=0.017)$. Over $70 \%$ of respondents were on the GP Specialist Register of the Irish Medical Council with $85 \%$ working in general practice. Nearly $30 \%$ of the sample was level 1-trained managing opioid users, while only $4.4 \%$ were level 2 -trained. There was no difference across gender in the practice population with the majority working in an urban area (43.7\%) with nearly $40 \%$ working in an area of deprivation. Selection bias is limited as all demographics of the responding group are consistent with the national data on GPs [32, 33] (Table 1).

\section{Statement responses}

The answer responses were examined by gender, age and training level. A significantly higher proportion of males compared with females (40.6 vs. $15.0 \% ; p<0.0001)$ agreed or strongly agreed that cannabis should be decriminalised, while more males than females also agreed that cannabis should be legalised for medical use $(p=0.002)$. There were no significant differences in the responses to the remaining questions by gender; for example, approximately $80 \%$ of both genders agreed that cannabis use has a significant effect on patients' mental health and increases the risk of schizophrenia $(77.3 \%)$, while over $60 \%$ of both males and females agreed that cannabis can have a role in pain management, multiple sclerosis and palliative care (Table 2).

When analysed by age, only $29 \%$ of those aged $<50$ years agreed that cannabis should be decriminalised. In contrast, a significantly higher proportion of those aged $>50$ years agreed that cannabis should be legalised for medical use compared to the younger GPs sampled (71.1 vs. $79.6 \% ; p=0.044)$. When analysed by level of training, a higher percentage of those who were level 1-trained agreed/strongly agreed cannabis should be legalised for medical use $(p=0.003)$. However, a significantly lower proportion of this group agreed/strongly agreed that cannabis has a role in pain management $(p=0.032)$, in treatment of multiple sclerosis $(p=0.037)$ and in palliative care $(p=0.047)$ compared to those who are not level 1-trained. In contrast, a higher percentage of those level 2-trained agreed/strongly agreed that cannabis should be decriminalised compared to those without this training (54.1 vs. $31.5 \% ; p=0.021$ ) (Tables 3, 4 and 5).

In the regression response predicator analysis, females were $66.2 \%$ less likely to agree that cannabis should be decriminalised, and $42.5 \%$ less likely to agree that cannabis should be legalised for medical use compared with males. Females were also 59.8 and $37.6 \%$ less likely to agree that cannabis has a role in palliative care and a role in the treatment of multiple sclerosis (respectively) than males. Furthermore, GPs based in a non-deprived area were $56.4 \%$ more likely to agree that cannabis has a role in pain management compared to those working in a deprived area, while GPs aged 30-50 years were $189.5 \%$ more likely to disagree that cannabis can have a 
Table 1 Participant characteristics

\begin{tabular}{|c|c|c|c|c|}
\hline & Total $(n$ 565) & Male (n 278) & Female (n 287) & $p$ value \\
\hline \multicolumn{5}{|l|}{ Age $n(\%)$} \\
\hline$<30$ years & $41(7.3)$ & $16(5.8)$ & $25(8.7)$ & 0.180 \\
\hline $30-50$ years & $300(53.2)$ & $121(43.7)$ & $179(62.4)$ & 0.288 \\
\hline$>50$ years & $223(39.5)$ & $140(50.5)$ & $83(28.9)$ & $<0.0001$ \\
\hline \multicolumn{5}{|l|}{ Membership of the ICGP $n(\%)$} \\
\hline Associate, part-time, others & $18(3.2)$ & $8(2.9)$ & $10(3.5)$ & 0.681 \\
\hline Full-time & $403(71.3)$ & $204(73.4)$ & $199(69.3)$ & 0.288 \\
\hline Retired & $36(6.4)$ & $24(8.6)$ & $12(4.2)$ & 0.030 \\
\hline Trainee & $108(19.1)$ & $42(15.1)$ & $66(23.0)$ & 0.017 \\
\hline \multicolumn{5}{|l|}{ Training $n(\%)$} \\
\hline On the GP specialist register & $435(77.5)$ & $216(78.3)$ & $219(76.8)$ & 0.687 \\
\hline Working in general practice & $482(85.3)$ & $242(87.1)$ & 240 (83.6) & 0.250 \\
\hline Working in academic general practice & $129(23.0)$ & $64(23.4)$ & $65(22.7)$ & 0.859 \\
\hline Level 1-trained GP managing opioid users & $169(29.9)$ & $77(27.7)$ & $92(32.1)$ & 0.258 \\
\hline Level 2-trained GP managing opioid users & $25(4.4)$ & $16(5.8)$ & $9(3.1)$ & 0.130 \\
\hline \multicolumn{5}{|l|}{ Practice population $n(\%)$} \\
\hline Mixed & $211(39.7)$ & $110(41.5)$ & $101(38.0)$ & 0.405 \\
\hline Rural & $88(16.6)$ & $42(15.8)$ & $46(17.3)$ & 0.655 \\
\hline Urban & $232(43.7)$ & $113(42.6)$ & $119(44.7)$ & 0.626 \\
\hline Working in an area of deprivation & $211(39.4)$ & $99(37.4)$ & $112(41.5)$ & 0.329 \\
\hline
\end{tabular}

Values are $n(\%)$; chi-square analysis for categorical variables for comparisons of distributions between gender

role in the treatment of multiple sclerosis compared to those not in that age group (Table 6).

\section{Discussion}

This study yielded unique findings with regard to Irish GP views on decriminalisation of cannabis and the medical use of cannabis (CTP). The majority of GPs did not support the decriminalisation of cannabis, but male respondents were significantly more likely to support this drug policy approach than their female counterparts. This majority view is contrary to current Irish government policy on the issue. Nearly $60 \%$ of GPs supported the legalisation of cannabis for medical use with older ( $>50)$ and male GPs more likely to favour this approach. In contrast to the view on decriminalisation, this majority view supports Irish government policy on CTP.

In 2000, the Irish Drug Related Knowledge, Attitudes and Beliefs survey found that males reported greater use of cannabis and knowledge of cannabis users than females [34]. This study, while dated, indicated that only $24 \%$ were in favour of legalisation of cannabis. Of interest is that the majority of GPs trained to a more

Table 2 Statement responses by gender

\begin{tabular}{|c|c|c|c|c|}
\hline & \multirow[t]{2}{*}{ Total } & \multicolumn{3}{|c|}{$n$ (\%) Agreed } \\
\hline & & Female & Male & $p$ value \\
\hline Cannabis should be decriminalised & $156(27.6)$ & $43(15.0)$ & $113(40.6)$ & $<0.0001$ \\
\hline Cannabis should be legalised for medical use & $331(58.6)$ & $146(50.9)$ & $185(66.5)$ & 0.002 \\
\hline The decriminalisation of cannabis use would lead to its increased use & $373(66.0)$ & $200(69.7)$ & $173(62.2)$ & 0.089 \\
\hline Cannabis use has a significant adverse effect on patients' mental health & $467(82.7)$ & $246(85.7)$ & $221(79.5)$ & 0.346 \\
\hline Cannabis use has a significant adverse effect on patients' physical health & $339(60.0)$ & $175(61.0)$ & $164(59.0)$ & 0.111 \\
\hline Cannabis use among young people increases the risk of schizophrenia & $437(77.3)$ & $228(79.4)$ & $209(75.2)$ & 0.990 \\
\hline Cannabis has a role to play in pain management & $359(63.5)$ & $166(57.8)$ & $193(69.4)$ & 0.511 \\
\hline Cannabis can have a role in the treatment of multiple sclerosis & $352(62.3)$ & $165(57.5)$ & $187(67.3)$ & 0.914 \\
\hline Cannabis can have a role in palliative care & $387(68.5)$ & $175(61.0)$ & $212(76.3)$ & 0.362 \\
\hline
\end{tabular}

Total agreed (strongly agree and agree). Values are $n(\%)$; chi-square analysis for categorical variables for comparisons of distributions between gender 
Table 3 Statement responses by age

\begin{tabular}{|c|c|c|c|}
\hline & $n(\%)$ Agre & & \\
\hline & $<50$ years & $>50$ years & $p$ value \\
\hline Cannabis should be decriminalised & $85(29.7)$ & $71(37.3)$ & 0.082 \\
\hline Cannabis should be legalised for medical use & $190(71.1)$ & $141(79.6)$ & 0.044 \\
\hline The decriminalisation of cannabis use would lead to its increased use & $232(82.2)$ & $141(82.4)$ & 0.960 \\
\hline Cannabis use has a significant adverse effect on patients' mental health & $281(92.4)$ & $185(92.5)$ & 0.978 \\
\hline Cannabis use has a significant adverse effect on patients' physical health & $210(81.3)$ & $128(81.5)$ & 0.973 \\
\hline Cannabis use among young people increases the risk of schizophrenia & $269(91.8)$ & $167(89.3)$ & 0.354 \\
\hline Cannabis has a role to play in pain management & $221(88.4)$ & $138(82.1)$ & 0.072 \\
\hline Cannabis can have a role in the treatment of multiple sclerosis & $208(92.4)$ & $144(87.8)$ & 0.123 \\
\hline Cannabis can have a role in palliative care & $235(90.0)$ & $152(85.3)$ & 0.139 \\
\hline
\end{tabular}

Total agreed (strongly agree and agree). Values are $n$ (\%); chi-square analysis for categorical variables for comparisons of distributions between age

specialist level in addictions supported decriminalisation (54.1\% $p=0.021)$. This may in part be due to their experience treating patients with opioid dependence in particular injecting drug users. In this patient cohort, cannabis use is often considered a secondary issue when managing the high-risk behaviour and health issues associated with injecting drug use. In contrast, in terms of gender, regression analyses revealed that females were less likely to agree that cannabis should be decriminalised. Prevalence data in Ireland has reported little change in women's rates of cannabis use, with prevalence rates highest among men and younger adults aged 15-34 years [35]. Research shows that individuals with personal experience of cannabis use are more inclined to be in favour of legalising [36]. According to the National Advisory Committee on Drugs and Alcohol (NACDA) in 2012 general population survey, the majority of respondents agreed with medical use of cannabis and disagreed with recreational use of cannabis. This is consistent with the drug policy approaches supported by Irish GPs in this survey.
Both genders of GPs in this study voiced concerns that decriminalisation would lead to increased use and the misuse of prescribed versions if available. Hall and Lynskey [37] speculate that potential effects of legalising recreational cannabis use, while substantially reducing the price, increasing excessive use and related harms, may also increase the number of new users. However, of interest, is recent reporting of a great overlap between medicinal and recreational cannabis use in the USA [38]. Regulating the cannabis market via prohibition and decriminalisation has a marginal effect on onset of cannabis use and population consumption rates [6]. Yuyan et al. [39] in their review of 38 countries indicated that cannabis liberalisation with depenalization and partial prohibition policies was associated with higher levels of regular cannabis use among adolescents. This is concerning given a recent Irish study [40] which underscored the relatively low levels of adolescent-perceived risk of mental and physical health problems with use of the drug. According to Eurobarometer [41], Ireland has the highest number of young people who have used

Table 4 Statement responses by training level (level 1)

\begin{tabular}{|c|c|c|c|}
\hline & \multicolumn{3}{|c|}{$n(\%)$ Agreed } \\
\hline & Not level 1 & Level 1 & $p$ value \\
\hline Cannabis should be decriminalised & $114(34.7)$ & $42(28.1)$ & 0.156 \\
\hline Cannabis should be legalised for medical use & $245(78.5)$ & $86(65.1)$ & 0.003 \\
\hline The decriminalisation of cannabis use would lead to its increased use & $264(83.0)$ & $109(80.1)$ & 0.464 \\
\hline Cannabis use has a significant adverse effect on patients' mental health & $321(92.2)$ & $146(92.9)$ & 0.767 \\
\hline Cannabis use has a significant adverse effect on patients' physical health & $229(80.3)$ & $110(83.9)$ & 0.377 \\
\hline Cannabis use among young people increases the risk of schizophrenia & $301(89.5)$ & $136(93.7)$ & 0.142 \\
\hline Cannabis has a role to play in pain management & $262(88.2)$ & $97(80.1)$ & 0.032 \\
\hline Cannabis can have a role in the treatment of multiple sclerosis & $257(92.4)$ & $95(85.5)$ & 0.037 \\
\hline Cannabis can have a role in palliative care & $282(90.0)$ & $105(83.3)$ & 0.047 \\
\hline
\end{tabular}

Total agreed (strongly agree and agree).Values are $n$ (\%); chi-square analysis for categorical variables for comparisons of distributions between level 1 training 
Table 5 Statement responses by training level (level 2)

\begin{tabular}{|c|c|c|c|}
\hline & $n(\%)$ Agree & & \\
\hline & Not level 2 & Level 2 & $p$ value \\
\hline Cannabis should be decriminalised & $143(31.5)$ & $13(54.1)$ & 0.021 \\
\hline Cannabis should be legalised for medical use & $313(74.1)$ & $18(81.8)$ & 0.422 \\
\hline The decriminalisation of cannabis use would lead to its increased use & $360(82.7)$ & $13(68.4)$ & 0.110 \\
\hline Cannabis use has a significant adverse effect on patients' mental health & $446(92.7)$ & $21(87.5)$ & 0.344 \\
\hline Cannabis use has a significant adverse effect on patients' physical health & $323(81.7)$ & $16(76.1)$ & 0.521 \\
\hline Cannabis use among young people increases the risk of schizophrenia & $416(90.6)$ & $21(95.4)$ & 0.443 \\
\hline Cannabis has a role to play in pain management & $341(85.6)$ & $18(90.0)$ & 0.588 \\
\hline Cannabis can have a role in the treatment of multiple sclerosis & $337(90.3)$ & $15(93.7)$ & 0.650 \\
\hline Cannabis can have a role in palliative care & $369(88.2)$ & $18(85.7)$ & 0.723 \\
\hline
\end{tabular}

cannabis in the past year (28\%), compared to a Europian Union (EU) average of $17 \%$; $58 \%$ of Irish youth have never taken cannabis, which in 2014 is third lowest in Europe and well below the EU average of $69 \%$. Overall, $46 \%$ of young Irish people consider regular cannabis use to be high risk, compared to an EU average of $63 \%$. The Eurobarometer in 2014 [41] also reported that 56\% of Irish 15-24-year-olds were of the view that the cannabis market should be regulated, which is almost a reverse position of the EU average, where $45 \%$ said cannabis should be regulated, and $53 \%$ said it should continue to be banned.

GPs in this national study agreed that cannabis use has a significant effect on patients' mental health and increases the risk of schizophrenia. Kondrad and Reid [25] have reported majority agreement of US physicians in Colorado regarding the serious mental and physical health risks of cannabis. Irish GPs in this study underscored their experience of the significant adverse effect on patient mental health and risks of schizophrenia in young users. Heavy use of cannabis at an earlier age is reported to heighten risk of dependence, depressive disorders, psychosis, suicidal ideation, development of schizophrenia and related negative social consequences [17]. This contributes to the debate around the cannabinoid hypothesis of psychosis, for example that exposure to cannabis and cannabinoid agonists is associated with psychosis outcomes through activation of CB1R [42-44]. However, to date, a causal relationship has not been established [4].

Kondrad and Reid [25] in their 2013 study of physician experiences and attitudes to medical cannabis reported that nearly half of participants did not support CTP and that only a minority thought therapeutic use of cannabis conferred physical and mental health benefits. Israeli practitioners in 2015 voiced partial acceptance for therapeutic use, and generally agreed that CTP could be helpful for chronic and for terminally ill patients [26]. However, oncologists and pain specialists did not agree unanimously that medical cannabis can undermine mental health, whereas other physicians did [26]. CTP is driven by public approval without scientific data routinely required to justify new medication regulation $[45,46]$. In 2005 , US physicians reported less support of CTP than the public [24]. Irish GPs who reported practicing in a non-deprived area in this study were more likely to agree that cannabis has a

Table 6 Statement response predicators

\begin{tabular}{|c|c|c|c|c|c|c|c|}
\hline & \multirow[t]{2}{*}{ Category } & \multirow[t]{2}{*}{ Variable } & \multirow[t]{2}{*}{ Beta } & \multirow[t]{2}{*}{$\operatorname{Exp}(B)$} & \multirow[t]{2}{*}{$p$ value } & \multicolumn{2}{|c|}{$95 \% \mathrm{Cl}$} \\
\hline & & & & & & lower & upper \\
\hline Cannabis should be decriminalised & Agree & Female & -1.084 & 0.338 & $<0.0001$ & 0.19 & 0.602 \\
\hline Cannabis should be legalised for medical use & Agree & Female & -0.553 & 0.575 & 0.017 & 0.365 & 0.907 \\
\hline \multirow[t]{3}{*}{ Cannabis has a role to play in pain management } & Agree & Female & -0.644 & 0.525 & 0.003 & 0.343 & 0.805 \\
\hline & Agree & Non-deprived area & 0.447 & 1.564 & 0.041 & 1.018 & 2.403 \\
\hline & Disagree & Not level 1 & -0.706 & 0.494 & 0.049 & 0.244 & 0.998 \\
\hline \multirow{2}{*}{$\begin{array}{l}\text { Cannabis can have a role in the treatment of } \\
\text { multiple sclerosis }\end{array}$} & Agree & Female & -0.472 & 0.624 & 0.019 & 0.42 & 0.926 \\
\hline & Disagree & Aged 30-50 years & 1.063 & 2.895 & 0.013 & 1.257 & 6.668 \\
\hline Cannabis can have a role in palliative care & Agree & Female & -0.91 & 0.402 & $<0.0001$ & 0.255 & 0.636 \\
\hline
\end{tabular}

Multi-nominal logistic regression analysis; reference category is neutral response 
role in pain management compared to those who reported working in a deprived area. Level of training for this Irish sample reflected that a greater percentage of those participants with level 1 substance misuse training agreed/ strongly agreed that cannabis should be legalised for medical use. While the clear majority of this group supported the role of medical cannabis in pain management, treatment of multiple sclerosis and palliative care, they were statistically less supportive than those without this training. Irish GPs aged 30-50 years were more likely to disagree that cannabis can have a role in the treatment of multiple sclerosis compared to those not in that age group. Kondrad and Reid [25] found that age was significantly associated with the recommendation of medical cannabis. They also found no significant association with physician gender, years in practice, or type of licence and recommendation of medical cannabis. In contrast, this study found that female GPs in Ireland were less likely to agree that cannabis should be legalised for medical use compared with males, and were also less likely to agree that cannabis has a role in palliative care or a role in the treatment of multiple sclerosis than males.

\section{Conclusions}

The study is unique in terms of describing Irish GP views on different drug policy approaches to cannabis use and is only one of a handful of studies worldwide that examines physicians' views on this topical issue. The majority of Irish GPs do not support decriminalisation of cannabis use which is now the policy choice of the Irish government. This study found interesting differences in views between male and female GPs and those with different levels of addiction training and experience. Female GPs tended to favour a more conservative drug policy approach, while those with more advanced training supported a more liberal one. The finding of majority support for CTP among Irish GPs in this study underpins and supports the proposed legislative changes that are presently being considered by the Irish parliament. While supporting this policy initiative, a clear majority of GPs viewed that such an approach had the potential to increase cannabis use and expressed concerns regarding both the mental and physical health risks associated with its use. This study captures the views of Irish GPs on potential policy changes regarding both medical and recreational cannabis use at a time when both are prohibited and will facilitate further research on how these views may change over time and be influenced by a different policy approach. Further research is warranted to explore how gender and levels of addiction training and experience impact doctors' views on drug policy.

\section{Abbreviations}

CTP: Cannabis for therapeutic purposes; EMA: European Medicines Agency; EU: European Union; GP: General practitioner; HPRA: Health Products
Regulatory Authority; ICGP: Irish College of General Practitioners; NACDA: National Advisory Committee on Drugs and Alcohol; UN: United Nations

\section{Acknowledgements \\ Funding \\ None \\ Availability of data and materials \\ Anonymised copies of the survey tool may be obtained upon request from des.crowley@icgp.ie.}

\section{Authors' contributions}

DC conceived the idea for the study, collected the data and revised the draught manuscript; CC contributed to the design of the study, coordinated the data collection, undertook the initial analysis and reviewed the manuscript; ID contributed to the design of the study and reviewed the manuscript; EL undertook quantitative data analysis and reviewed the manuscript; and MCVH contributed to the design of the study, undertook the survey review, qualitative data analysis, manuscript drafting and review of the final submission. All authors read and approved the final manuscript.

\section{Authors' information}

DC is the Assistant Director of the Substance Misuse Programme in Irish College of General Practitioners, Dublin, Ireland.

CC is the Director of research in Irish College of General Practitioners, Dublin, Ireland.

ID is the Director of the Substance Misuse Programme in Irish College of General Practitioners, Dublin, Ireland.

EL is a postdoctoral researcher in the School of Biochemistry and Immunology, Trinity College Dublin, Dublin, Ireland.

$\mathrm{MCVH}$ is a senior Marie Sklodowska-Curie Actions fellow in the School of Health Sciences, Waterford Institute of Technology, Waterford, Ireland, and is a clinical audit specialist of the Substance Misuse Programme in Irish College of General Practitioners, Dublin, Ireland.

\section{Competing interests}

The authors received no financial support from any organisation for the submitted work; no financial relationships with any organisations that might have an interest in the submitted work in the previous 3 years and no other relationships or activities that could appear to have influenced the submitted work.

\section{Consent for publication}

The corresponding author has the right to grant on behalf of all authors and does grant on behalf of all authors consent for publication.

\section{Ethics approval and consent to participate}

Irish College of General Practitioners

\section{Author details}

${ }^{1}$ School of Health Sciences, Waterford Institute of Technology, Waterford, Ireland. ${ }^{2}$ rrish College of General Practitioners, Dublin, Ireland. ${ }^{3}$ School of Biochemistry and Immunology, Trinity College Dublin, Dublin, Ireland.

Received: 8 July 2016 Accepted: 23 December 2016

Published online: 13 January 2017

\section{References}

1. Hall W, Renstrom M, Poznyak V. The health and social effects of nonmedical cannabis use. Geneva: World Health Organization; 2016.

2. Kilmer B. Policy designs for cannabis legalization: starting with the eight Ps. Am J Drug Alcohol Abuse. 2014:40:259-61.

3. Rehm J, Fischer B. Cannabis legalization with strict regulation, the overall superior policy option for public health. Clin Pharmacol Ther. 2015:97:541-4.

4. International Centre for Science in Drug Policy. State of the evidence: cannabis use and regulation. Toronto: International Centre for Science in Drug Policy; 2015. p. 41. 
5. European Monitoring Centre for Drugs and Drug Addiction. Cannabis policy: status and recent developments. 2016. http://www.emcdda.europa. eu/topics/cannabis-policy\#section1. Accessed 16 Aug 2016.

6. van den Brink W. Forum: decriminalization of cannabis. Curr Opin Psychiatry. 2008;21:122-6.

7. Clark AJ, Ware MA, Yazer E, Murray TJ, Lynch ME. Patterns of cannabis use among patients with multiple sclerosis. Neurology. 2004;62:2098-100.

8. Chu YWL. The effects of medical marijuana laws on illegal marijuana. Health Econ. 2014;38:43-61.

9. Sznitman SR, Bretteville-Jensen AL. Public opinion and medical cannabis policies: examining the role of underlying beliefs and national medical cannabis policies. Harm Reduct J. 2015;12:46

10. Joy JE, Watson SJ, Benson JA. Marijuana and medicine: assessing the science base. Washington, DC: National Academy Press; 1999.

11. Abrams DI, Jay CA, Shade SB, Vizoso H, Reda H, Press S, et al. Cannabis in painful HIV-associated sensory neuropathy: a randomized placebocontrolled trial. Neurology. 2007;68:515-21.

12. Wilsey B, Marcotte T, Tsodikov A, Millman J, Bentley H, Gouaux B, et al. A randomized, placebo-controlled, crossover trial of cannabis cigarettes in neuropathic pain. J Pain. 2008;9:506-21.

13. Ellis RJ, Toperoff W, Vaida F, van den Brande G, Gonzales J, Gouaux B, et al. Smoked medicinal cannabis for neuropathic pain in HIV: a randomized, crossover clinical trial. Neuropsychopharmacology. 2009;34:672-80.

14. Bushlin I, Rozenfeld R, Devi LA. Cannabinoid-opioid interactions during neuropathic pain and analgesia. Curr Opin Pharmacol. 2010;10:80-6.

15. Ware MA, Wang T, Shapiro S, Robinson A, Ducruet T, Huynh T, et al. Smoked cannabis for chronic neuropathic pain: a randomized controlled trial. CMAJ. 2010;182:e694-701.

16. Schlossarek S, Kempkensteffen J, Reimer J, Verthein U. Psychosocial determinants of cannabis dependence: a systematic review of the literature. Eur Addict Res. 2016;22:131-44

17. Nussbaum AM, Boyer JA, Kondrad EC. "But my doctor recommended pot": medical marijuana and the patient-physician relationship. J Gen Intern Med. 2011:26:1364-7.

18. Hall W, Weier M. Assessing the public health impacts of legalizing recreational cannabis use in the USA. Clin Pharmacol Ther. 2015:97:607-15.

19. Sznitman SR, Zolotov Y. Cannabis for therapeutic purposes and public health and safety: a systematic and critical review. Int J Drug Policy. 2015;26:20-9.

20. Ziemanski D, Capler R, Tekanoff R, Lacasse A, Luconi F, Ware M. Cannabis in medicine: a national educational needs assessment among Canadian physicians. BMC Med Edu. 2015;15:52.

21. Troutt WD, DiDonato MD. Medical cannabis in Arizona: patient characteristics, perceptions, and impressions of medical cannabis legalization. J Psychoactive Drugs. 2015;47:259-66.

22. Schwartz RH, Voth EA, Sheridan MJ. Marijuana to prevent nausea and vomiting in cancer patients: a survey of clinical oncologists. South Med J. 1997:90:167-72

23. Doblin RE, Kleiman MA. Marijuana as antiemetic medicine: a survey of oncologists' experiences and attitudes. J Clin Oncol. 1991:9:1314-9.

24. Charuvastra A, Friedmann PD, Stein MD. Physician attitudes regarding the prescription of medical marijuana. J Addict Dis. 2005;24:87-93.

25. Kondrad E, Reid A. Colorado family physicians' attitudes toward medical marijuana. J Am Board Fam Med. 2013;26:52-60.

26. Ebert T, Zolotov Y, Eliav S, Ginzburg O, Shapira I, Magnezi R. Assessment of Israeli physicians' knowledge, experience and attitudes towards medical cannabis: a pilot study. Isr Med Assoc J. 2015;17:437-41.

27. Ablin JN, Elkayam O, Fitzcharles MA. Attitudes of Israeli rheumatologists to the use of medical cannabis as therapy for rheumatic disorders. Rambam Maimonides Med J. 2016;7:e0012. Published Online First: Apr 19 2016. doi: 10.5041/RMMJ.10239PMCID.

28. Bellerose D, Carew A, Lyons S. Trends in treated problem drug use in Ireland 2005 to 2010. Dublin: Health Research Board (HRB); 2011.

29. VanGeest JB, Johnson TP, Welch VL. Methodologies for improving response rates in surveys of physicians: a systematic review. Eval Health Prof. 2007; 30(4):303-21.

30. Byrne M, Doherty S, McGee H, Murphy AW. General practitioner views about discussing sexual issues with patients with coronary heart disease: a national survey in Ireland. BMC Fam Pract. 2010:10:11-40.

31. O'Shea MT, Collins C. A survey of GP experience with the work of the National Cancer Control Programme and their views in relation to service priorities. Dublin: Irish College of General Practitioners; 2016.
32. Crowley P. Health inequalities and Irish general practice in areas of deprivation. Dublin: Irish College of General Practitioners; 2005.

33. O'Shea MT, Collins C. Access to diagnostics used to detect cancer. Dublin: Irish College of General Practitioners and Irish Cancer Society; 2016.

34. Bryan A, Farrell E, Moran R, O'Brien M. Drug-related knowledge, attitudes and beliefs in Ireland: report of a nation-wide survey. Dublin: Health Research Board (HRB); 2000.

35. National Advisory Committee on Drugs and Alcohol (NACDA). General population survey on drug prevalence 2010/2011. Dublin: NACDA; 2012.

36. Williams J, van Ours J, Grossman M. Attitudes to legalizing cannabis use. Health Econ Early Online: 1 Apr 2016. doi:10.1002/hec.3340.

37. Hall W, Lynskey M. Evaluating the public health impacts of legalizing recreational cannabis use in the USA. Addiction Early Online: 15 Apr 2016. doi:10.1111/add.13428.

38. Pacula RL, Jacobson M, Maksabedian EJ. In the weeds: a baseline view of cannabis use among legalizing states and their neighbours. Addiction. 2016; 111:973-80.

39. Yuyan S, Michela L, Ruopeng A. Cannabis liberalization and adolescent cannabis use: a cross-national study in 38 countries. PLoS ONE. 2015;10: e0143562.

40. Barrett $P$, Bradley C. Attitudes and perceived risk of cannabis use in Irish adolescents. Ir J Med Sci. 2016:185:643-7. Early Online: 4 July 2015.

41. EUROBAROMETER. Flash Eurobarometer 401: Young people and drugs. Brussels: EUROBAROMETER: TNS Political \& Social; 2014

42. McLaren JA, Silins E, Hutchinson D, et al. Assessing evidence for a causal link between cannabis and psychosis: a review of cohort studies. Int J Drug Policy. 2010;21:10-9.

43. Sewell RA, Skosnik PD, Garcia-Sosa I, Ranganathan M, D'Souza DC. Behavioral, cognitive and psychophysiological effects of cannabinoids: relevance to psychosis and schizophrenia. Rev Bras Psiquiatr. 2010;32:S15-30.

44. Radhakrishnan R, Addy PH, Sewell RA, D'Souza D. Cannabis, cannabinoids, and the association with psychosis. In: Madras B, Kuhar MJ, editors. The effects of drug abuse on the human nervous system. Oxford: Elsevier; 2012. p. 423-58.

45. Bostwick JM. Blurred boundaries: the therapeutics and politics of medical marijuana. Mayo Clin Proc. 2012:87:172-86.

46. Porche DJ. Legalization of medical marijuana (cannabis). Am J Mens Health. 2013;7:449.

\section{Submit your next manuscript to BioMed Central and we will help you at every step:}

- We accept pre-submission inquiries

- Our selector tool helps you to find the most relevant journal

- We provide round the clock customer support

- Convenient online submission

- Thorough peer review

- Inclusion in PubMed and all major indexing services

- Maximum visibility for your research

Submit your manuscript at www.biomedcentral.com/submit
) Biomed Central 